J. Akademika Kim. 6(1): 65-71, February 2017

ISSN 2302-6030 (p), 2477-5185 (e)

\title{
MENINGKATKAN AKTIVITAS DAN HASIL BELAJAR SISWA PADA PEMBELAJARAN KIMIA PENYETARAAN REAKSI REDOKS MELALUI LESSON STUDY DI KELAS XII IPA SMA NEGERI 2 PALU
}

\author{
Improving of Student's Activities and Their Learning Outcomes on Equalization \\ Redox Reaction Topic Through Lesson Study in Class XII IPA SMA Negeri 2 \\ Palu
}

\author{
*Chairunnisa, Supriadi, dan Nurdin Rahman \\ Pendidikan Kimia/FKIP - Universitas Tadulako, Palu - Indonesia 94118 \\ Recieved 16 December 2016, Revised 20 January 2017, Accepted 21 February 2017
}

\begin{abstract}
The research about the balancing of redox reaction on chemistry subject has been done. This research was conducted on class XII IPA8 SMA Negeri 2 Palu with 28 of student, in the first semester of academic year 2014/2015. The research method used is a descriptive qualitative in which data processing use percentages and rating scale. The data is collected by observation sheets, questionnaires and documentation. Implementation of lesson study on class XII IPA8 SMA Negeri 2 Palu is conducted in three meetings time (open class) with 3 phases; plan, do and see respectively. Based on the results obtained every meeting by researcher, the data activity of students is rising by $54.93 \%, 59.86 \%$ and $74.30 \%$. Furthermore, at the third meeting, the data obtained is an excellent category which means the student's activity in the lesson study is increased. These proves that through the lesson study can increase the activity of the learning process of students. In addition, based on the data analysis of the student's learning outcomes during three meeting times is increased. Average of completeness of student's learning outcomes of every meeting is $67.85 \%, 85.71 \%$ and $100 \%$, respectively. Again, these proves that the student's learning outcomes by clasical can be incresed through the lesson study.
\end{abstract}

Keywords: Lesson Study, Learning Activities, Learning Outcomes, Equalization Of Redoks, Chemistry

\section{Pendahuluan}

Suatu model pembinaan guru untuk mencapai kualitas pembelajaran di sekolah adalah lesson study. Lesson study yaitu suatu model pembinaan profesi pendidikan melalui pengkajian pembelajaran secara kolaboratif dan berkelanjutan berlandaskan prinsipprinsip kolegalitas dan mutual learning untuk membangun komunitas belajar. Lesson study dilaksanakan dalam 3 tahapan yaitu merencanakan (plan), melaksanakan (do), dan merefleksi (see) yang berupa kegiatan yang berkelanjutan (Rustono, 2008).

Lesson study memposisikan siswa sebagai pusat pembelajaran. Guru tidak hanya mentrasfer materi ajar, tetapi memberikan motivasi dan inspirasi kepada siswa untuk

\section{*Correspondence:}

Chairunnisa

Program Studi Pendidikan Kimia, Fakultas Keguruan dan Ilmu Pendidikan, Universitas Tadulako

email: chairunnisauntad@gmail.com

Published by Universitas Tadulako 2017 berkreasi dan mandiri. Melalui lesson study, siswa bias berdialog dan berinteraksi dengan sesama siswa secara terbuka dan interaktif di bawah bimbingan guru sehingga terpacu untuk menguasai bahan ajar yang disajikan. Siswa didorong untuk aktif terlibat memahami materi yang diajarkan, tidak hanya menjadi penonton dan pendengar setia (Undang, 2009).

Permasalahan pembelajaran yang perlu mendapat pemecahan adalah rendahnya aktivitas siswa pada setiap pembelajaran di dalam kelas dan rendahnya hasil belajar siswa. Rendahnya aktivitas dan hasil belajar peserta didik disebabkan pembelajaran yang digunakan masih berpusat pada guru. Guru cenderung mentransfer informasi kepada siswa. Guru belum menggunakan model pembelajaran yang bervariasi dalam pembelajaran dan tidak melengkapi diri dengan perangkat pembelajaran sehingga kegiatan pembelajaran kurang sistematis. Perangkat pembelajaran 
yang terdiri dari silabus, RPP, LKS, bahan ajar, model, dan media pembelajaran serta tes hasil belajar. Salah satu model pembelajaran yang dapat meningkatkan aktivitas dan hasil belajar siswa adalah model kooperatif berbasis lesson study (Susanto, 2012).

Berdasarkan portofolio dan wawancara guru mengenai hasil belajar siswa di SMA Negeri 2 Palu menyatakan bahwa materi kimia penyetaraan reaksi redoks hasil belajarnya masih sangat rendah dan sulit untuk mengaktifkan siswa. Hasil wawancara siswa SMA Negeri 2 Palu menyatakan bahwa pelajaran kimia merupakan salah satu pelajaran yang sulit, terutama materi yang berhubungan dengan reaksi-reaksi kimia. Pokok bahasan penyetaraan reaksi redoks menggunakan sistem latihan, menghafal, pemberian tugas, tidak jarang digunakan. Pembelajaran akan lebih efektif apabila siswa dilibatkan langsung atau berperan aktif selama proses pembelajaran. Kenyataan ini memberikan gambaran bahwa perlu kita mencari suatu pendekatan dan strategi pembelajaran yang dapat meningkatkan aktivitas dan hasil belajar siswa. Salah satu pembelajaran kimia yang mengaktifkan siswa dan memperbaiki pembelajaran adalah pembelajaran lesson study.

Lesson study atau studi pelajaran adalah peningkatan pembelajaran dan proses membangun pengetahuan yang bermula pada pendidikan dasar Jepang. Guru lesson study di Jepang bekerja dalam tim kecil untuk merencanakan, mengajar, mengamati, menganalisis, dan memperbaiki pelajaran kelas individu, disebut penelitian pelajaran. Hampir semua guru Jepang berpartisipasi dalam tim studi pelajaran selama tahun ajaran. Disamping itu, mereka mengamati penelitian pembelajaran dengan teratur di sekolah mereka yang mempunyai pembelajaran bagi khalayak umum. Pada dasarnya lesson study Jepang adalah berbasis luas, guru yang dipimpin sistem untuk perbaikan pengajaran dan pembelajaran (Cerbin \& Kopp, 2006).

\section{Metode}

Populasi dari penelitian ini adalah siswa kelas XII IPA SMA Negeri 2 Palu tahun pelajaran 2014/2015 yang terdiri dari 8 kelas yang berjumlah 223 siswa. Sampel pada penelitian ini adalah siswa kelas XII IPA8 SMA Negeri
2 Palu tahun pelajaran 2014/2015 berjumlah 28 orang siswa. Pemilihan kelas ini berdasarkan pertimbangan bahwa kelas tersebut memiliki prestasi belajar kimia masih rendah. Variabel bebas dalam penelitian ini adalah lesson study, yang terdiri dari plan, do dan see. Variabel terikat dalam penelitian ini adalah hasil belajar kimia dan aktivitas siswa dalam proses pembelajaran. Instrumen penelitian ini adalah tes hasil belajar kimia, berupa soal esai 5 soal dan lembar observasi aktivitas siswa yang terdiri dari 8 item merupakan angket yang diisi oleh observer pada saat pembelajaran berlangsung dengan memberikan skor yang berskala 1 sampai 5 dalam tiap pernyataan. Skor (5) adalah SB: Sangat Baik, skor (4) B : Baik, skor (3) C : Cukup, skor (2) K : Kurang, Skor (1) sangat kurang. Pelaksanaan observasi dilakukan dengan mengisi format lembar observasi aktivitas siswa dengan tujuan untuk memgetahui aktivitas siswa saat pembelajaran berlangsung. Untuk menganalisis dan menentukan persentase ketuntasan belajar siswa menggunakan rumus persentase ketuntasan klasikal.

\section{Hasil dan Pembahasan}

Pembelajaran lesson study pada mata pelajaran kimia dilaksanakan di kelas XII IPA8 berjumlah 28 orang siswa. Pembelajaran dilakukan sebanyak 3 kali open class dapat diuraikan menjadi pembelajaran-I, pembelajaran-II, pembelajaran-III. Pokok bahasan yang diajarkan dalam pembelajaran lesson study ini yaitu penyetaraan reaksi redoks. Tahap pelaksanaan dimulai dari plan yang dilakukan sebanyak 3 kali, do sebanyak 3 kali dan see 3 kali pertemuan. Pada tahap plan guru model beserta para observer berkumpul berdiskusi tentang persiapan pada saat pembelajaran baik mengenai perangkat pembelajaran, instrumen penilaian maupun lembar observasi.

Prinsip-prinsip yang harus dianut dalam pembelajaran lesson study adalah: (a) Prinsip keterbukaan yaitu kesediaan guru untuk diobservasi saat pembelajaran. (b) Prinsip kebersamaan yaitu pemberian masukan, catatan tentang fakta dalam pelaksanaan pembelajaran di ruang kelas. (c) Prinsip pemahaman diri yaitu memberikan kesempatan kepada siswa untuk melakukan proses pemahaman terhadap pembelajaran. (d) Prinsip pengenalan diri 
yaitu memberikan kesempatan kepada siswa untuk mencoba-coba alat pembelajaran baru. (e) Prinsip penyesuaian diri yaitu menciptakan suasana pembelajaran sesuai dengan jenjang dan tingkatan kelas agar siswa menjadi lebih aktif. (f) Prinsip kolaboratif yaitu penerapan proses pembelajaran secara bersama-sama atau kolaborasi (Haryoto dkk., 2010)

Langkah awal dalam kegiatan lesson study yaitu tahap perencanaan, melakukan pertemuan untuk membicarakan hal-hal yang terkait dengan kepentingan pelaksanaan pembelajaran yakni menyusun rancangan pembelajaran yang dituangkan dalam Rencana Pelaksanaan Pembelajaran (RPP), Lembar Kerja Siswa (LKS), pembentukan kelompok, lembar observasi, dan tata tertib pengamat atau observer. Siswa dikatakan tuntas individu jika persentase daya serap individu sekurangkurangnya $75 \%$ dan ketuntasan klasikal dicapai adalah 85\% (Winarsih \& Mulyani, 2012).

Pelibatan seluruh siswa untuk dapat aktif dalam proses pembelajaran sangat diperlukan. Dalam kelompok kooperatif, pembelajaran menjadi sebuah aktivitas yang bias membuat para siswa lebih unggul diantara teman-teman sebayanya. Beberapa kajian yang dilakukan oleh Deutsch dan Thomas telah menunjukkan bahwa ketika para siswa bekerja bersamasama untuk meraih sebuah tujuan kelompok, membuat mereka mengekspresikan normanorma yang baik dalam melakukan apa pun yang diperlukan untuk keberhasilan kelompok (Melati, 2011).

Tabel 1. Data Indikator Angket Aktivitas

\begin{tabular}{cccc}
\multicolumn{3}{c}{ Siswa } \\
\hline No & Indikator Angket & Skor indikator & Skor dengan 5 observer \\
\hline 1. & Sangat baik & 40 & 200 \\
2. & Baik & 32 & 160 \\
3. & Cukkip & 24 & 120 \\
4. & Kurang & 16 & 80 \\
5. & Sangat kurang & 8 & 40 \\
\hline
\end{tabular}

Bahan ajar dapat berupa buku ajar yang berupa buku materi wajib, buku pendamping maupun Lembar Kerja Siswa (LKS). Siswa dalam era zaman sekarang dituntut untuk aktif dalam pembelajarannya. Salah satu cara yang ditempuh oleh guru dalam mengaktifkan belajar siswa adalah dengan menggunakan LKS. Lembar kerja siswa digunakan sebagai
Tabel 2. Hasil Diskusi Lesson Study Tahap

$$
\text { Perencanaan (Plan) }
$$

\begin{tabular}{|c|c|c|}
\hline No & Diskusi & $\begin{array}{l}\text { Hal Yang Perlu Ditindak Lanjuti } \\
\end{array}$ \\
\hline 1. & $\begin{array}{l}\text { Rencana } \\
\text { Pelaksanaan } \\
\text { Pembelajaran }\end{array}$ & $\begin{array}{l}\text { 1) Semua anggota lesson study menyusun RPP lalu mendiskusikan } \\
\text { baik tujuan pembelajaran, indikator, model pembelajaran yang } \\
\text { digunakan dan sampai evaluasi yang akan diberikan pada pertemuan } \\
\text { pertama. } \\
\text { 2) Guru model bertugas mempresentasikan RPP yang sudah } \\
\text { didiskusikan. }\end{array}$ \\
\hline 2. & LKS & $\begin{array}{l}\text { Lembar kerja siswa dibagikan setiap siswa, agar siswa dalam kelompok } \\
\text { aktif semua. }\end{array}$ \\
\hline & Kelompok & $\begin{array}{l}\text { 1) Siswa dibagi menjadi } 5 \text { kelompok. Pengelompokkan dilakukan } \\
\text { secara heterogen } \\
\text { 2) Setiap siswa diberi nomor punggung sesuai nomor urut absent. }\end{array}$ \\
\hline & $\begin{array}{l}\text { Lembar } \\
\text { Observasi }\end{array}$ & 1) Lembar observasi dibagikan sebelum observer masuk dalam kelas \\
\hline & $\begin{array}{l}\text { Tata tertib } \\
\text { Observer }\end{array}$ & $\begin{array}{l}\text { 2) Tata tertib disosialisasikan sebelum melaksanakan } d o \text { di kelas. } \\
\text { 3) Masing-masing observer mengamati } 1 \text { kelompok. }\end{array}$ \\
\hline
\end{tabular}

acuan untuk memandu pelaksanaan kegiatan belajar mengajar. LKS dapat dianggap sebagai suatu media atau alat pembelajaran karena dipergunakan guru sebagai media dalam melaksanakan kegiatan pengajaran untuk mencapai tujuan pembelajaran (Saidah dkk., 2014).

Lembar Kerja Siswa (LKS) merupakan salah satu jenis alat bantu pembelajaran. Secara umum, LKS merupakan perangkat pembelajaran sebagai pelengkap atau sarana pendukung pelaksanaan Rencana Pembelajaran (RP). Lembar Kerja Siswa adalah panduan siswa yang digunakan untuk melakukan kegiatan penyelidikan atau pemecahan masalah. Lembar Kerja Siswa dapat berupa panduan untuk latihan pengembangan semua aspek pembelajaran dalam bentuk panduan eksperimen atau demonstrasi (Ningtiyas \& Siswaya, 2012)

Lesson study bukan merupakan suatu strategi ataupun metode pembelajaran, tetapi kegiatan lesson study dapat menerapkan berbagai strategi dan metode pembelajaran yang dapat disesuaikan dengan situasi dan kondisi serta permasalahan yang dihadapi guru pada setiap proses pembelajaran (Khaeriyah dkk., 2011).

Tahap perencanaan bertujuan untuk merancang pembelajaran yang dapat mengajarkan siswa (mahasiswa) bagaimana berpartisipasi aktif dalam kegiatan pembelajaran. Tahap pelaksanaan merupakan tahap penerapan rancangan pembelajaran yang telah disusun sebelumnya. Selama proses pembelajaran berlangsung pengamat menfokuskan perhatian kepada aktivitas siswa (mahasiswa) yaitu interaksi sesama siswa (mahasiswa), siswa dengan guru (mahasiswa dengan dosen), siswa (mahasiswa) dengan bahan ajar serta interaksi siswa (mahasiswa) 
dengan lingkungan. Setelah selesai proses pembelajaran, langsung dilakukan diskusi antara guru (dosen) model dengan pengamat. Mula-mula guru (dosen) model menyampaikan kesan-kesan selama proses pembelajaran berlangsung, lalu dilanjutkan oleh para pengamat. Pengamat harus menyampaikan fakta temuannya di kelas secara jujur dan bijak demi perbaikan proses pembelajaran. Guru (dosen) model harus dapat menerima masukan dari pengamat untuk perbaikan pembelajaran pada tahap berikutnya. Pada prinsipnya, semua orang yang terlibat dalam kegiatan lesson study harus memperoleh buah pembelajaran (lesson learn). Dengan demikian kegiatan lesson study dapat digunakan untuk membangun komunitas belajar (learning community) (Elvinawati dkk., 2012).

Tahap kedua yaitu tahap pelaksanaan (do), tahap dilaksanakan oleh seorang guru model dan 5 observer. Guru model dan para observer bersama-sama masuk kelas. Para observer harus mengambil posisi di belakang atau di samping sepanjang tidak menganggu aktivitas pembelajaran. Observer mengamati semua ak $\neg$ tivitas peserta didik selama proses observasi pem-belajaran. Ia juga dapat merekam semua aktivitas pembelajaran dengan alat yang sudah disiapkan (kamera, handycam, atau cctv) (Akhmad dkk., 2014).

Table 3. Hasil Observasi Aktivitas Siswa

\begin{tabular}{|c|c|c|c|}
\hline \multicolumn{4}{|c|}{ Pertemuan I,II Dan III } \\
\hline Pertemuan & Observer & Jumlah Nilai & Persentase (\%) \\
\hline \multirow{5}{*}{ I } & Observer- 1 & 131 & 54,58 \\
\hline & Observer-2 & 128 & 53,33 \\
\hline & Observer- 3 & 98 & 49,00 \\
\hline & Observer- 4 & 118 & 59,00 \\
\hline & Observer -5 & 141 & 58,75 \\
\hline \multirow{5}{*}{ II } & Observer -1 & 141 & 58,75 \\
\hline & Observer- 2 & 136 & 56,66 \\
\hline & Observer- 3 & 108 & 54,00 \\
\hline & Observer- 4 & 129 & 64,50 \\
\hline & Observer -5 & 157 & 65,41 \\
\hline \multirow{5}{*}{ III } & Observer -1 & 175 & 72,91 \\
\hline & Observer- 2 & 183 & 76,25 \\
\hline & Observer- 3 & 145 & 72,50 \\
\hline & Observer- 4 & 153 & 76,50 \\
\hline & Observer -5 & 176 & 73,33 \\
\hline & Rata & 141.27 & 63.03 \\
\hline
\end{tabular}

Persentase aktivitas siswa dalam pertemuan-I sebesar 54,93\% ini diperoleh dari hasil angket data aktivitas yang memperoleh nila skor 123,20. Nilai ini tidak jauh dari nilai tengah antara kriteria cukup dan kriteria baik. Berdasarkan pengamatan semua observer menyatakan bahwa siswa belum belajar tentang topik pembelajaran atau belum mempelajari kembali materi redoks karena masih ada materi yang belum mereka pahami. Ketika ditanyakan materi redoks pada kelas X mereka tidak menjawab. Selain itu juga hasil pengamatan observer I masih ada siswa yang tidak terlibat aktif yaitu pada 45 menit berlangsungnya proses pembelajaran, terlihat ada siswa yang mengantuk, berisik, keluar masuk kelas, mengganggu siswa lain, melamun, usil dan coret-coret kertas. Pada pengamatan observer 2 beberapa orang siswa ada yang berisik, mengerjakan tugas lain, mengganggu siswa lain dan pindah-pindah tempat duduk. Pada pengamatan observer 3 ada dua orang siswa yang melamun ketika guru menjelaskan, ada siswa yang usil dan aktivitas belajarnya sangat kurang. Pengamatan observer 4 ada beberapa siswa yang mengantuk dan melamun. Sedangkan pada pengamatan observer 5 banyak siswa yang mengantuk, ada yang usil dan mengerjakan tugas lain. Dari data tersebut terlihat aktivitas siswa dalam proses belajar masih kurang. Hal ini disebabkan bahwa pada pertemuan-1 siswa masih merasa asing dikelilingi oleh para observer dimana biasanya hanya ditemani seorang guru di kelas. Dan juga karena mereka belum ada persiapan materi dari rumah, sehinggah mereka belum aktiv menanggapi materi yang diajarkan.

Persentase aktivitas siswa dalam pertemuanII sebesar $59,86 \%$ ini diperoleh dari hasil angket data aktivitas yang memperoleh nila skor 134,20 nilai mendekati kriteria baik. berarti pada pertemuan-2 siswa mulai beradaptasi dengan suasana belajar yang dikelilingi oleh para observer, selain itu juga hasil pengamatan observer siswa yang tidak terlibat aktif di pertemuan-1 sudah mulai aktif pada pertemuan-2. Berdasarkan pengamatan observer, siswa sudah serius mendengarkan penjelasan guru, sudah belajar dengan baik dan memperhatikan materi yang diajarkan, hanya ada beberapa siswa saja yang masih teralihkan perhatiannya karena mengantuk, dan diganggu oleh temannya yang lain.

Persentase aktivitas siswa dalam pertemuanIII sebesar $74,30 \%$ ini diperoleh dari hasil angket data aktivitas yang memperoleh nila skor 166,40 nilai mendekati kriteria sangat baik. 
Hal ini disebabkan pada pertemuan-3 siswa rata-rata mulai aktif belajar, selain itu juga hasil pengamatan observer siswa yang tidak terlibat aktif sudah menurun dibandingkan pertemuan sebelumnya. Berdasarkan pengamatan observer 1 pada kelompok oksidasi, hanya satu orang siswa yang tidak terlibat aktif dalam proses belajar mengajar, siswa ini pindah-pindah tempat duduk. Pengamatan observer 2 pada kelompok reduksi terlihat seorang siswa yang mengantuk. Pengamatan observer 3 pada kelompok redoks terlihat seorang siswa yang mengganggu siswa lain. Pengamatan observer 4 pada kelompok ion terlihat seorang siswa yang berisik. Pengamatan observer 5 pada kelompok elektron terlihat semua siswa telah aktif dalam proses belajar mengajar. Pada pertemuan ketiga ini, umumnya semua siswa sudah belajar dengan baik. Beberapa siswa tersebut yang tercatat dalam pengamatan observer pada kegiatan siswa yang tidak terlibat dalam proses belajar mengajar merupakan siswa yang selalu menjadi sorotan guru dan observer pada setiap pertemuan. Namun, pada pertemuan ketiga ini persentase aktivitas siswa sudah sangat baik dibandingkan pertemuan sebelumnya.

Seorang guru harus dapat menciptakan suasana belajar yang kondusif dan dapat meningkatkan aktivitas dan kreativitas siswa selama proses pembelajaran. Guru harus dapat membelajarkan siswa dengan menggunakan berbagai sumber belajar. Siswa dimotivasi untuk menemukan sendiri dan belajar sendiri atau bekerja sama dengan teman dalam menemukan solusi dari berbagai permasalahan yang dihadapi dalam proses belajar mengajar. $\mathrm{Hal}$ ini akan membuat siswa mandiri dan punya inisiatif untuk selalu ingin tahu, ingin mencoba menemukan berbagai alternatif jawaban melalui sumber yang ada disekitarnya, baik berupa buku sumber, melalui teman, dan sumber belajar lainnya. Guru harus dapat menciptakan suasana belajar yang menarik dan menyenangkan, sehingga siswa termotivasi untuk belajar. Jika siswa termotivasi untuk belajar diharapkan aktivitas siswa dalam belajar meningkat, akhirnya membawa dampak terhadap hasil belajar siswa yang diharapkan juga meningkat (Murtiani dkk., 2012).

Berdasarkan penelitian yang dilakukan maka diperoleh hasil belajar siswa setiap pertemuan yang diperoleh dari data tes esai pada kelas lesson study.

Tabel 4. Rekapitulasi Ketuntasan Hasil Belajar Siswa

\begin{tabular}{cccc}
\hline Ketuntasan & Pertemuan-1 & Pertemuan-2 & Pertemuan-3 \\
\hline Tuntas & $67,85 \%$ & $85,71 \%$ & $100,00 \%$ \\
\hline Tidak tuntas & $32,14 \%$ & $14,29 \%$ & $0,00 \%$ \\
\hline
\end{tabular}

Hasil olahan data tersebut menunjukkan bahwa kenaikan persentase ketuntasan klasikal kelas lesson study pada pertemuan pertama sampai pertemuan ketiga memberikan data dengan angka $67,86 \% ; 85,71 \%$, dan $100,00 \%$. Secara umum hasil yang diperoleh siswa pada pertemuan kedua ini sudah sangat baik. Karena siswa yang tuntas sudah mencapai 24 orang dari 28 orang jumlah siswa atau sekitar $85,71 \%$, sedangkan siswa yang belum tuntas bersisa 4 orang atau sekitar 14,29\%. Ini berarti pelaksanaan lesson study pertemuan-2 ada peningkatan dari pertemuan-1. Hasil olahan data pada pertemuan-2 sudah tergambar hasilnya mencapai ketuntasan daya serap pembelajaran minimal $75 \%$ dan ketuntasan klasikal $80 \%$. Hasil yang diperoleh disajikan dalam Gambar 1

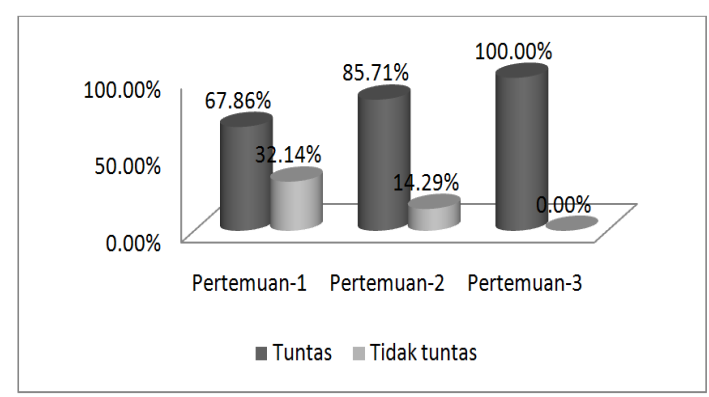

Gambar 1. Rata-Rata Persentase Ketuntasan Hasil Belajar Kelas Lesson Study

Data diatas dapat dilihat bahwa pembelajaran lesson study sangat baik dan cocok diterapkan pada pengembangan kurikulum dalam meningkatkan standar proses dan standar kelulusan setiap kompetensi mata pelajaran khususnya pelajaran kimia. Lesson study adalah pendekatan yang paling cocok untuk memberikan guru melaju kesempatan untuk memperdalam pengetahuan mereka tentang materi pelajaran serta pengetahuan psychogogic, yaitu, bagaimana memimpin pikiran pelajar dengan kebutuhan khusus dalam hal ini, melalui kerja sama dengan rekan-rekan 
lainnya. Oleh karena itu, kolaborasi merupakan landasan LS dan sebagai tempat untuk guru berbagi pengalaman dan pengetahuan mengajar dengan orang lain (Chia, 2013).

Tahap ketiga yaitu tahap refleksi proses pembelajaran dilaksanakan segera setelah pelaksanaan pembelajaran. Hal ini dimaksudkan agar semua kejadian penting yang telah terjadi tidak terlupakan dalam melakukan refleksi. Kegiatan ini merupakan tahapan yang sangat penting karena merupakan upaya perbaikan proses pembelajaran berdasarkan pengamatan terhadap pelaksanaan pembelajaran yang telah dilaksanakan. Dari hasil tindakan (Do) dan pengamatan observer, diperoleh gambaran secara umum bahwa guru model telah berupaya melaksanakan pembelajaran dengan baik yang dapat meningkatkan aktivitas dan minat siswa dalam proses pembelajaran. Secara keseluruhan pembelajaran lesson study adalah jelas bahwa siswa merespon positif terhadap kerja kelompok. Pentingnya untuk mematuhi pandangan bahwa lesson study bukan tentang mengkritisi instruktur; bukan, harus fokus pengamatan belajar siswa. Namun, ada kesempatan untuk memberikan umpan balik (Groningen \& Bennett, 2012).

Berdasarkan observasi penelitian aktivitas dan hasil belajar siswa pada kelas Lesson study setiap pertemuan yang diperoleh disajikan dalam Gambar 2

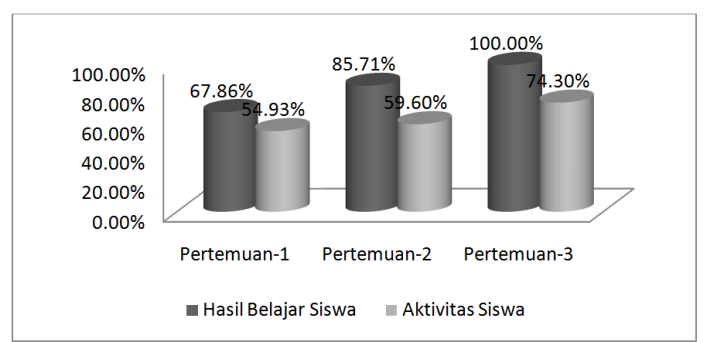

Gambar 2. Hasil Reakapitulasi Hubungan Antara Aktivitas Dan Hasil Belajar

Hasil olahan data antara aktivitas dan hasil belajar pada setiap pertemuan terlihat pada grafik bahwa hubungan kenaikan aktivitas belajar setiap pertemuan dengan hasil belajar ada peningkatan. Data diatas memberikan kesimpulan sementara bahwa semakin meningkat aktivitas siswa dalam pembelajaran maka hasil belajarnya juga meningkat. Jika aktivitas belajar siswa meningkat dan hasil belajar siswa meningkat, berarti kualitas pembelajaran meningkat. Meningkatnya hasil belajar, suasana kelas yang aktif terjadinya sharing informasi dengan adanya kolaborasi antar guru dan obsever sehingga lesson study dapat dilaksanakan atau diterapkan di semua mata pelajaran (Wahyuni, 2013).

\section{Kesimpulan}

Pembelajaran kimia penyetaraan reaksi redoks melalui lesson study dapat meningkatkan aktivitas belajar siswa dimana data hasil yang diperoleh berkategori sangat baik artinya melalui pembelajaran lesson study dapat meningkatkan aktivitas belajar siswa. Lesson study dapat meningkatkan hasil belajar siswa hal ini membuktikan bahwa ketuntasan klasikal belajar siswa melebihi ketuntasan yang telah ditetapkan oleh standar kelulusan dan standar proses kurikulum. Ini membuktikan bahwa semakin meningkat aktivitas siswa dalam pembelajaran maka hasil belajar siswa akan lebih baik sehingga kualitas pembelajaran siswa akan lebih baik khususnya mata pelajaran kimia di SMA Negeri 2 Palu.

\section{Ucapan Terima Kasih}

Penulis mengucapkan terima kasih kepada Badrah Lahay kepala sekolah SMA Negeri 2 Palu, Satria dan Kurniyati guru mata pelajaran kimia SMA Negeri 2 Palu yang telah banyak membantu selama penelitian.

\section{Referensi}

Akhmad, S., Haryono, \& Fakhruddin. (2014). Pengembangan model supervisi klinis dengan pendekatan lesson study untuk meningkatkan kompetensi profesional guru bahasa inggris SMA Negeri di kabupaten Cilacap. Journal of Educational Research and Evaluation, 3(1), 1-11.

Cerbin, W., \& Kopp, B. (2006). Lesson study as a model for building pedagogical knowledge and improving teaching. International Journal of Teaching and Learning in Higher Education, 18(3), 1-8.

Chia, N. K. H. (2013). A psychogogic perspective of lesson study for special education teachers. Journal Academic Research International, 4(4), 1-13.

Elvinawati, Sumpono, \& Amir, H. (2012). Lesson study pada mata kuliah kimia sekolah I sebagai upaya peningkatan kualitas 
pembelajaran dan pembangunan karakter (character building). Jurnal Exacta, $X(2)$, $1-4$.

Groningen, A. P. v., \& Bennett, S. (2012). Lesson study collaboration, improvement, and reflection. International Journal of Applied Science and Technology, 2(8), 1-6.

Haryoto, Lestari, M. D., \& Suseno, N. A. (2010). Pengelolaan pembelajaran lesson study mata pelajaran IPA di SMA Negeri 1 Nogosari kabupaten Boyolali. Jurnal Pendidikan, 19(1), 1-8.

Khaeriyah, S., Shofiyati, Maliku, A., \& Yetty, D. (2011). Implementasi lesson studi menerapkan model STAD untuk meningkatkan interaksi. eksplorasi, dan motivasi siswa pada bahasa dispersi di kelas XII IPA SMA Negeri 1 Pontianak Jurnal Pendidikan Matematika dan IPA, 2(2), 1-11.

Melati, H. A. (2011). Meningkatkan aktivitas dan hasil belajar siswa SMAN I Sungai Ambawang melalui pembelajaran model advance organizer berlatar numbered heads together (NHT) pada materi kelarutan dan hasil kali kelarutan. Jurnal Visi Ilmu Pendidikan, 6(3), 1-12.

Murtiani, Fauzan, A., \& Wulan, R. (2012). Penerapan pendekatan contextual teaching and learning (CTL) berbasis lesson study dalam meningkatkan kualitas pembelajaran fisika di SMP Negeri kota Padang. Jurnal Penelitian Pembelajaran Fisika, 1(1), 1-21.
Ningtiyas, P., \& Siswaya, H. (2012). Penggunaan metode kooperatif tipe TGT dilengkapi modul dan LKS ditinjau dari aktivitas siswa. Jurnal Penelitian Pembelajaran Fisika, 3(1), 1-8.

Rustono, W. S. (2008). Meningkatkan kemampuan mahasiswa menerapkan strategi pembelajaran melalui lesson study di sekolah dasar. Jurnal Pendidikan Dasar(10), 1-7.

Saidah, N., Parmin, \& Dewi, N. R. (2014). Pengembangan LKS IPA terpadu berbasis problem based learning melalui lesson study tema ekosistem dan pelestarian lingkungan. Unnes Science Education Journal, 3(2), 1-8.

Susanto, J. (2012). Pengembangan perangkat pembelajaran berbasis lesson study dengan kooperatif tipe numbered heads together untuk meningkatkan aktivitas dan hasil belajar IPA di SD. Journal of Primary Educational, 1(2), 1-7.

Undang, G. (2009). Lesson Study Model Pengkajian Pembelajaran Kolaboratif. Bandung: Sayagatama Press.

Wahyuni, S. (2013). Optimalisasi pembelajaran melalui pelaksanaan lesson study. Jurnal Pendidikan Almuslim, 1(1), 1-5.

Winarsih, A., \& Mulyani, S. (2012). Peningkatan profesionalisme guru ipa melalui lesson study dalam pengembangan model pembelajaran PBI. Jurnal Pendidikan IPA Indonesia, 1(1), 43-50. 